\title{
Assignment of complex species by affinity capillary electrophoresis: the case of $\mathrm{Th}(\mathrm{IV})$-desferrioxamine B
}

Vladimir Sladkov, ${ }^{1, *}$ Jérôme Roques, ${ }^{1}$ and Michel Meyer ${ }^{2}$

1 Université Paris-Saclay, CNRS/IN2P3, IJCLab, 91405 Orsay, France

2 Institut de Chimie Moléculaire de l'Université de Bourgogne (ICMUB), UMR 6302, CNRS, Université Bourgogne-Franche-Comté, 9 avenue Alain Savary, BP 47870, 21078 Dijon Cedex, France

Accepted June 13, 2020 in

Electrophoresis 2020, 41, 1870-1877

doi : $10.1002 /$ elps.202000114

Correspondence: Dr Vladimir Sladkov, Université Paris-Saclay, CNRS/IN2P3, IJCLab, 91405 Orsay, France

E-mail: sladkov@ipno.in2p3.fr

(iD) 0000-0002-1053-0473 (Vladimir Sladkov)

(iD) 0000-0003-2295-7826 (Michel Meyer) 


\begin{abstract}
The electrophoretic mobility change of desferrioxamine B (DFO) was monitored by UV absorption spectrophotometry upon increasing the thorium(IV) concentration in the background electrolyte at two acidities $\left(\left[\mathrm{HClO}_{4}\right]_{\mathrm{Tot}}=0.0316\right.$ and $\left.0.0100 \mathrm{M}\right)$. These data enabled to assess the speciation model and to determine the equilibrium constant of $\left[\mathrm{Th}(\mathrm{DFO}) \mathrm{H}_{2}\right]^{3+}$ at fixed ionic strength $\left(I=0.1 \mathrm{M}(\mathrm{H}, \mathrm{Na}) \mathrm{ClO}_{4}\right)$. Affinity capillary electrophoresis (ACE) turned out to be most helpful in identifying the complexed species by ascertaining its charge and protonation state. The assignment of the correct stoichiometry relied on the reliable estimation of the electrophoretic mobility by assuming similar hydrodynamic radii for (DFO) $\mathrm{H}_{4}{ }^{+}$and the chelate. The value of the apparent equilibrium constant $\left(\log \beta_{112}=38.7 \pm 0.4\right)$ obtained by ACE compares favorably well with those reported in the literature for thorium and a range of other metal ions, according to a linear free-energy relationship. This method is useful for studying metal-ligand binding equilibria and provides valuable information for further modelling the behavior of tetravalent actinides under environmental conditions. Structural information about the prevalent solution species in acidic conditions was gained by DFT calculations, confirming the bishydroxamato coordination mode of $\mathrm{Th}^{4+}$ by the diprotonated ligand.
\end{abstract}

\title{
Keywords:
}

Affinity capillary electrophoresis / Complexation / Stability constants / Thorium / Desferrioxamine B / DFT 


\section{Introduction}

The study of metal-ion complex formation equilibria in aqueous solutions is an important research endeavor in coordination chemistry. However, understanding the speciation of each constituent in a particular matrix or sample at preset temperature and pressure, in other words knowing the distribution and concentration of all specific chemical forms in which the components might occur [1], is of much broader interest and has wide outreaches. Acquiring complexation data (chemical composition and structural formulas, concentration-based stability constants, reaction enthalpies and entropies, heat capacities...) further allows modelling and predicting the fate of metals and ligands in multicomponent systems under thermodynamic control by varying simultaneously one or more factors such as the concentration of components or competing agents, $\mathrm{pH}$, temperature, pressure, salinity, ionic strength. Such results have become an essential asset for workers and decision makers in such diverse fields as toxicology, clinical and biological chemistry, geochemistry and environmental chemistry, analytics and industrial processes [2].

The thermodynamic parameters associated to the formation of metallic complexes involving either inorganic or organic ligands are classically derived from titration experiments by solving the mass-balance equations for each constituent. The most commonly used analytical methods are absorption or emission spectrophotometry (UV-vis-NIR), NMR spectroscopy, potentiometry, and calorimetry (ITC), as the measured quantities are proportional to the concentration or mole fraction of the detected solutes. One of the major difficulties in modelling the chemical equilibria is related to the correctness of the hypothesized stoichiometry of the various species prevailing in solution. However, none of these techniques is able to differentiate species merely by their electrical charge. In that respect, attempts to use electrospray-ionization mass spectrometry (ESI-MS) have been reported [3-5]. In spite of the mild ionization processes and rapid solvent evaporation in the source, both the abundance and nature of the gas-phase species do not necessarily mirror the solution speciation at a given concentration level [6,7], as equilibria for labile species are displaced while droplets are concentrating.

In that respect, electro-migration techniques are appealing, as they introduce an additional dimension in building the chemical model and identifying the species in equilibrium. Affinity capillary electrophoresis (ACE) has been successfully applied for metal/ligand speciation studies and the determination of the associated equilibrium constants in the case of labile (kinetically rapid) systems, for which the rate of ligand exchange between the various bound and unbound forms is substantially faster than the characteristic migration rate in the 
capillary [8-14]. This method turned out to be extremely useful for solution thermodynamic investigations involving precious ligands [15-17] or highly radiotoxic metals such as actinides [9,18-25], because of the extremely low consumption of the detected reagent. Only few nanoliters, typically about 5-25 nL, are introduced in the injection loop, while sample concentrations classically range between $10^{-5}-10^{-3} \mathrm{M}$ for an UV-vis detection $[9,26]$, but they can be as low as $10^{-12}-10^{-6} \mathrm{M}$ when ACE is hyphenated with an ICP-MS instrument $[9,18,24]$. Besides, another major advantage is the commercial availability of fully automated instrumentation.

The aim of this work was to demonstrate the advantages of ACE over other classical methods applied in solution coordination studies. As a part of our ongoing interest in tetravalent actinide chelation [27,28] with strong binders, including siderophores, we have focused our attention on the Th(IV)/desferrioxamine B (DFO) system in an attempt to clarify the speciation model (vide infra) [29]. DFO (Figure 1) is an ubiquitous bacterial siderophore produced by Streptomyces pilosus, which is commercialized under the tradename Desferal ${ }^{\circledR}$ as an in vivo iron and aluminum decorporating agent. Siderophores are water-soluble, low molecular weight iron(III) carriers [30], which are common in soils, natural waters but also in the marine environment [31,32]. Recently, they have also been recognized as effective actinide(IV) chelators and transporters [33], promoting the soil migration of plutonium in accidentally contaminated areas [34]. Endowed with three hydroxamate binding units and a terminal primary amine that does not take part in coordination, hexadentate $\mathrm{DFO}^{3-}$ (Figure 1) is a weak tetraprotic base. Depending on the $\mathrm{pH}$, the ligand forms bis- and trishydroxamato complexes with all metal ions having coordination numbers equal to or higher than 6 , while single chelated species might also be observed at low $\mathrm{pH}$ with some cations [35].

Whisenhunt et al. investigated the speciation of the $\mathrm{Th}^{4+} / \mathrm{DFO}^{3-}$ system in aqueous solution $(I=0.1 \mathrm{M} \mathrm{KCl})$ by glass-electrode potentiometry, UV absorption spectrophotometry, and ${ }^{1} \mathrm{H}$ NMR spectroscopy over a large proton concentration range $\left(\mathrm{p}[\mathrm{H}]=-\log \left[\mathrm{H}^{+}\right]=0.81-\right.$ 10.7) [29]. Potentiometric titration data $\left([\mathrm{Th}]_{\mathrm{Tot}}=1.25 \times 10^{-3} \mathrm{M},[\mathrm{DFO}]_{\mathrm{Tot}}=1.35 \times 10^{-3} \mathrm{M}\right)$ could be best reproduced by assuming the formation of four mononuclear complexes of $\left[\mathrm{Th}(\mathrm{DFO}) \mathrm{H}_{h}\right]^{(1+h)+}$ composition, with $h$ ranging between 3 and -1 . The latter species was assigned to the neutral monohydroxo complex $[\mathrm{Th}(\mathrm{DFO})(\mathrm{OH})]$, while for $[\mathrm{Th}(\mathrm{DFO})]^{+}(h=0)$ the primary amine was supposed to remain fully deprotonated and unbound. Under mild acidic conditions (i.e. $\mathrm{p}[\mathrm{H}]<2$ ), data modeling suggested the occurrence of two protonated complexes $\left[\mathrm{Th}(\mathrm{DFO}) \mathrm{H}_{3}\right]^{4+}$ and $\left[\mathrm{Th}(\mathrm{DFO}) \mathrm{H}_{2}\right]^{3+}$ in equilibrium, although the refined $\mathrm{p} K_{\mathrm{a}}$ values were considered as abnormal (1.8 and 2.7, respectively). In turn, spectrophotometric titrations 
performed at $\mathrm{p}[\mathrm{H}]=0.81-2.9$ and 25-fold lower metal and ligand concentrations were interpreted by assuming a direct dissociation of $\left[\mathrm{Th}(\mathrm{DFO}) \mathrm{H}_{2}\right]^{3+}$, while an additional ${ }^{1} \mathrm{H}$ NMR titration experiment also enabled to possibly rule out the existence of $\left[\mathrm{Th}(\mathrm{DFO}) \mathrm{D}_{3}\right]^{4+}$ in $\mathrm{D}_{2} \mathrm{O}$ at $\mathrm{pD} 1.1-5.5\left(\mathrm{pD}=-\log a_{\mathrm{D}^{+}}\right.$, where $a_{\mathrm{D}^{+}}$stands for the deuteron activity).

Herein, we are demonstrating how ACE with UV detection can be advantageously used to solve the aforementioned ambiguity regarding the thorium(IV) speciation in the presence of desferrioxamine $\mathrm{B}$ at low $\mathrm{pH}$, while determining at the same time a reliable and consistent value of the equilibrium constant. DFT calculations were carried out to provide structural information of the major species in solution that further supported our electrophoretic data analysis.

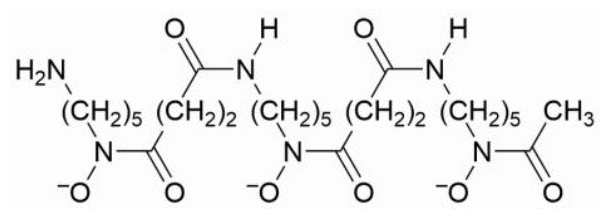

Figure 1. Molecular structure of $\mathrm{DFO}^{3-}$, the conjugated base of desferrioxamine $\mathrm{B}$.

\section{Materials and methods}

\subsection{Chemicals}

All chemicals and reagents used were of analytical grade. Concentrated perchloric acid (60\%, Sigma-Aldrich) was diluted in water to the required concentration. Sodium perchlorate monohydrate $(\geq 99 \%)$ was purchased by Merck. The mesylate salt of tetraprotonated desferrioxamine B (Desferal ${ }^{\circledR}$ ) was used as received from Apollo Scientific. $\mathrm{Th}\left(\mathrm{NO}_{3}\right)_{4} \cdot 4 \mathrm{H}_{2} \mathrm{O}$ was supplied by Prolabo. All solutions were prepared with fresh, high-purity deionized water $(R=18.2 \mathrm{M} \Omega \mathrm{cm})$ produced by a Millipore direct Q cartridge system.

Caution! Thorium (primary isotope ${ }^{232} \mathrm{Th}$ ) is a weak $\alpha$-emitter (3.95 and 4.01 MeV) with a half-life of $1.405 \times 10^{10}$ years and a specific activity of $4.07 \times 10^{4} \mathrm{~Bq} / \mathrm{g}$. All manipulations and reactions should be carried out in monitored fume hoods, in a laboratory equipped with $\alpha$ - and $\gamma$-counting equipment.

\subsection{Apparatus and Software}

Affinity capillary electrophoregrams were acquired on a P/ACE MDQ (Beckman Coulter) instrument equipped with a $0-30 \mathrm{kV}$ high-voltage built-in power supply and a diode array detector. UV direct detection at $\lambda=200 \mathrm{~nm}$ was used in this work. The fused silica capillary 
(Beckman Instruments) of $50 \mu \mathrm{m}$ internal diameter, $363 \mu \mathrm{m}$ outer diameter, $31.2 \mathrm{~cm}$ total length $\left(L_{\mathrm{t}}\right)$, and $21 \mathrm{~cm}$ effective separation length $\left(L_{\mathrm{d}}\right)$, was housed in an interchangeable cartridge with a circulating liquid coolant that maintained the temperature at $25^{\circ} \mathrm{C}$. Prior to use, the capillary was preconditioned by successive washes with $0.1 \mathrm{M} \mathrm{NaOH}$ solutions, deionized water, and the background electrolyte (BGE) solution under study $\left(I=0.1 \mathrm{M}(\mathrm{H}, \mathrm{Na}) \mathrm{ClO}_{4}\right)$. In between two runs, it was rinsed for $3 \mathrm{~min}$ at a pressure of $103.4 \mathrm{kPa}$ with the BGE solution or kept filled with deionized water when stored overnight.

Samples containing [(DFO) $\left.\mathrm{H}_{4}\right] \mathrm{CH}_{3} \mathrm{SO}_{3}\left(10^{-4} \mathrm{M}\right)$ were injected for $4 \mathrm{~s}$ at a pressure of $3.45 \mathrm{kPa}$ at the positive capillary end in the normal polarity mode. The latter was filled first with a solution of BGE containing increasing amounts of thorium(IV) $\left(0-5 \times 10^{-3} \mathrm{M}\right)$. The applied potential was $5 \mathrm{kV}$, as required by the Ohm's law. The current intensity value was about $45 \mu \mathrm{A}$ and the input power about $0.2 \mathrm{~W}$. Under these conditions, heating through the Joule effect in the thermostated part of the capillary remains insignificant as the actual temperature did not deviate by more than $1{ }^{\circ} \mathrm{C}$ from the set value of $25^{\circ} \mathrm{C}$. Non-thermostated capillary inlet has no influence on stability constant values obtained under such conditions [36,37]. Separations were performed at constant forward pressure of $1.4 \mathrm{kPa}$. For each experimental condition, the migration times of the analyte $(t)$ and of the system peak of water $\left(t_{\text {eof }}\right)[38]$ were taken as the mean value of three independent measurements. Data acquisition and processing were carried out with the Karat 32 software (Beckman Coulter, France). The apparent electrophoretic mobility, $\mu_{\mathrm{obs}}\left(\mathrm{m}^{2} \mathrm{~s}^{-1} \mathrm{~V}^{-1}\right)$, was calculated by using Eq. (1), where $L_{\mathrm{t}}$ is the total capillary length $(\mathrm{m}), L_{\mathrm{d}}$ is the length between the capillary inlet and the detection window $(\mathrm{m})$, and $U$ is to the applied voltage $(\mathrm{V})$. All calculations were done with EXCEL ${ }^{\circledR}$ and the implemented Solver module for nonlinear least-squares refinement of the stability constants.

$$
\mu_{\mathrm{obs}}=\frac{L_{\mathrm{t}} L_{\mathrm{d}}}{U}\left(\frac{1}{t}-\frac{1}{t_{\mathrm{eof}}}\right)
$$

The proton concentration (throughout, $\mathrm{p}[\mathrm{H}]$ stands for $-\log \left[\mathrm{H}^{+}\right]$) in the injected solutions was maintained constant by adding the required amount of $\mathrm{HClO}_{4}$ to reach either $0.0316(\mathrm{p}[\mathrm{H}]=1.50)$ or $0.0100 \mathrm{M}(\mathrm{p}[\mathrm{H}]=2.00)$. Before injection, the $\mathrm{pH}$ defined as $-\log a_{\mathrm{H}^{+}}$ of each sample was checked by using a GLP-21 (Crison, France) pH-meter connected to a combined glass electrode calibrated against NIST standard buffer solutions ( $\mathrm{pH} 4.01$ and 7.00) with a precision of \pm 0.05 unit. 


\subsection{DFT calculations}

Structures were optimized using the density functional theory (DFT) approach as implemented in the Gaussian09 package [39] with the hybrid B3LYP functional [40]. The MWB60 Stuttgart relativistic effective core potentials [41] were used to describe the thorium atom and the $6-311++\mathrm{G}^{* *}$ basis set for the others. Solvation effects were partially taken into account by applying the conductor-like polarizable continuum model (CPCM) implemented in Gaussian09 with a dielectric constant of $\varepsilon_{0}=80$ [42].

\section{Results and discussion}

\subsection{Affinity capillary electrophoresis}

Owing to the pronounced tendency of $\mathrm{Th}^{4+}$ to hydrolyze and to form polynuclear hydroxo complexes in acidic media [43], the $\mathrm{p}[\mathrm{H}]$ of all solutions was kept constant either at 1.50 or 2.00 by adding the required amount of perchloric acid to the BGE, while maintaining the ionic strength at $0.1 \mathrm{M}$ with sodium perchlorate. Distribution diagrams computed for total thorium concentrations varying between $10^{-7}$ and $10^{-3} \mathrm{M}$ and the critically evaluated equilibrium constants recommended by the Nuclear Energy Agency Thermochemical Data Base for $I=0.1$ M (Figure S1) [43], indicate that the $\mathrm{Th}^{4+}$ aqua ion predominates $(97.8$ and $93.3 \%$ at $\mathrm{p}[\mathrm{H}] 1.5$ and 2.0, respectively) over $\mathrm{Th}(\mathrm{OH})^{3+}$ (2.2 and 6.6\%, respectively). Moreover, the molar fractions of $\mathrm{Th}^{4+}$ and $\mathrm{Th}(\mathrm{OH})^{3+}$ remain constant over the explored concentration range. Thus, the contribution of hydrolyzed species to the logarithm of overall stability constants of mononuclear thorium complexes can be neglected, since the values are underestimated by a systematic error equal to $\log \left(1+10^{-3.15} /\left[\mathrm{H}^{+}\right]\right)$. The highest bias $(\sim 0.03$ at $\mathrm{p}[\mathrm{H}] 2)$ is well below the precision achieved by ACE measurements ( $\geq 0.1 \log$ unit).

Below $\mathrm{p}[\mathrm{H}] 6$, tetraprotic desferrioxamine $\mathrm{B}$ is present in aqueous solution as the fully protonated (DFO) $\mathrm{H}_{4}{ }^{+}$monovalent cation (Figure S2), which strongly absorbs UV light under $260 \mathrm{~nm}\left(\lambda_{\max }=205 \mathrm{~nm}, \varepsilon=17600 \mathrm{M}^{-1} \mathrm{~cm}^{-1}\right.$ [29] $)$. Whisenhunt et al. have also shown that thorium binding gives rise to a typical band centered at $230 \mathrm{~nm}\left(\varepsilon=17600 \mathrm{M}^{-1} \mathrm{~cm}^{-1}\right)$, with a significant absorption around $200 \mathrm{~nm}$ [29]. Accordingly, an experimental ACE setup equipped with an UV detector could be used to monitor the migration in the capillary, despite the fact that thorium(IV) is spectroscopically silent, unlike uranium(VI) [6,44]. Hence, all injected samples contained a fixed amount of ligand $\left(10^{-4} \mathrm{M}\right)$, while runs were made in triplicates using $\mathrm{HClO}_{4} / \mathrm{NaClO}_{4}$ solutions as $\mathrm{BGE}(I=0.1 \mathrm{M})$ containing increasing amounts of thorium(IV) $(0$ 
$\left.5 \times 10^{-3} \mathrm{M}\right)$. Figure 2 shows typical electropherograms recorded at $\mathrm{p}[\mathrm{H}] 1.50$, similar traces were obtained at $\mathrm{p}[\mathrm{H}]$ 2.00. In all cases, a single peak was detected, supporting a fast ligand exchange at the separation time scale (i. e. few minutes) between the free and complexed ligand species [45]. This result is in perfect agreement with the water self-exchange rate constant $\left(k_{\text {ex }}\right.$ $\left.>5 \times 10^{7} \mathrm{~s}^{-1}\right)$ at $298 \mathrm{~K}$ reported for $\mathrm{Th}\left(\mathrm{H}_{2} \mathrm{O}\right)_{10}{ }^{4+}$ by Farkas et al. [46]. According to Eq. (1), the shift to shorter times of the peak with increasing thorium concentration suggests that the complexes have a higher mobility than $(\mathrm{DFO}) \mathrm{H}_{4}{ }^{+}$.

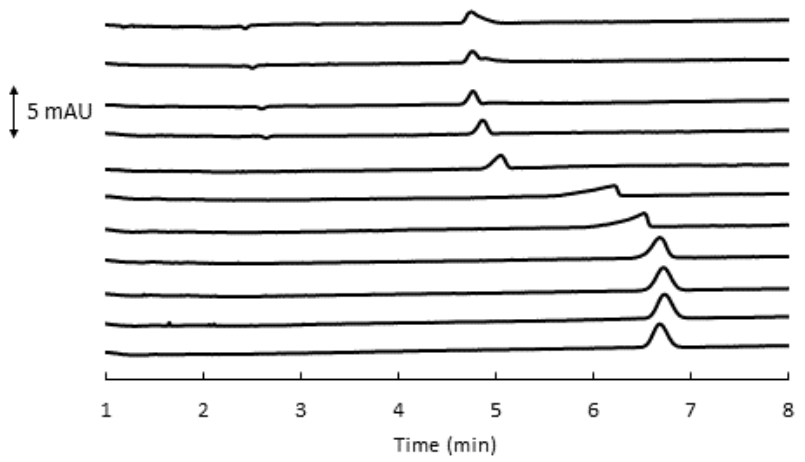

Figure 2. Electrophoregrams of desferrioxamine $B\left(10^{-4} \mathrm{M}\right)$ in the presence of different amounts of Th(IV) in the BGE. From bottom to top: $[\mathrm{Th}(\mathrm{IV})]_{\mathrm{Tot}}=0,10^{-7}, 5 \times 10^{-7}, 10^{-6}, 5 \times$ $10^{-6}, 10^{-5}, 5 \times 10^{-5}, 10^{-4}, 2 \times 10^{-4}, 5 \times 10^{-4}, 10^{-3} \mathrm{M} . \mathrm{I}=0.1 \mathrm{M}(\mathrm{H}, \mathrm{Na}) \mathrm{ClO}_{4},\left[\mathrm{HClO}_{4}\right]=0.0316$ $\mathrm{M}(\mathrm{p}[\mathrm{H}]=1.50), T=298(1) \mathrm{K}, t_{\mathrm{inj}}=4 \mathrm{~s}, \Delta P_{\mathrm{inj}}=3.45 \mathrm{kPa}, U=5 \mathrm{kV}$; capillary: $L_{\mathrm{t}}=31.2 \mathrm{~cm}$, $L_{\mathrm{d}}=21 \mathrm{~cm}, \varnothing_{\mathrm{int}}=50 \mu \mathrm{m}$; UV-detection: $\lambda=200 \mathrm{~nm}$.

The variation of the experimental electrophoretic mobility $\left(\mu_{\mathrm{obs}}\right)$ as a function of the total Th(IV) concentration in the BGE was found to be essentially identical at both investigated $\mathrm{p}[\mathrm{H}]$ values of 1.50 and 2.00 (Figure 3 and Table S3), suggesting a very similar species distribution in both conditions. At very low metal concentrations ([Th $\left.]_{\mathrm{Tot}} \leq 10^{-6} \mathrm{M}\right), \mu_{\mathrm{obs}}$ tends to the limiting value of $(7.8 \pm 0.2) \times 10^{-9} \mathrm{~m}^{2} \mathrm{~V}^{-1} \mathrm{~s}^{-1}$ observed in the absence of Th(IV) that corresponds to the intrinsic mobility of (DFO) $\mathrm{H}_{4}{ }^{+}\left(\mu_{\mathrm{LH}_{4}}\right)$. Conversely, $\mu_{\mathrm{obs}}$ reaches also a plateau value close to $2.5 \times 10^{-8} \mathrm{~m}^{2} \mathrm{~V}^{-1} \mathrm{~s}^{-1}$ in the concentration range $(0.2-1) \times 10^{-3} \mathrm{M}$, suggesting the nearly complete formation a definite complex. Noteworthy, upon increasing further the total thorium concentration in the BGE (up to $5 \times 10^{-3} \mathrm{M}$ ), a significant increase of $t_{\text {eof }}$ could be noticed. This change in the electroosmotic flow might be due to sorption phenomena of $\mathrm{Th}^{4+}$ and of its hydrolysis products on the wall of the silica capillary $[47,48]$. Since the surface 
modification by the analyte introduced systematic errors on the migration times, all experimental $\mu_{\mathrm{obs}}$ values measured above $10^{-3} \mathrm{M}$ were discarded (data not shown in Figure 3).

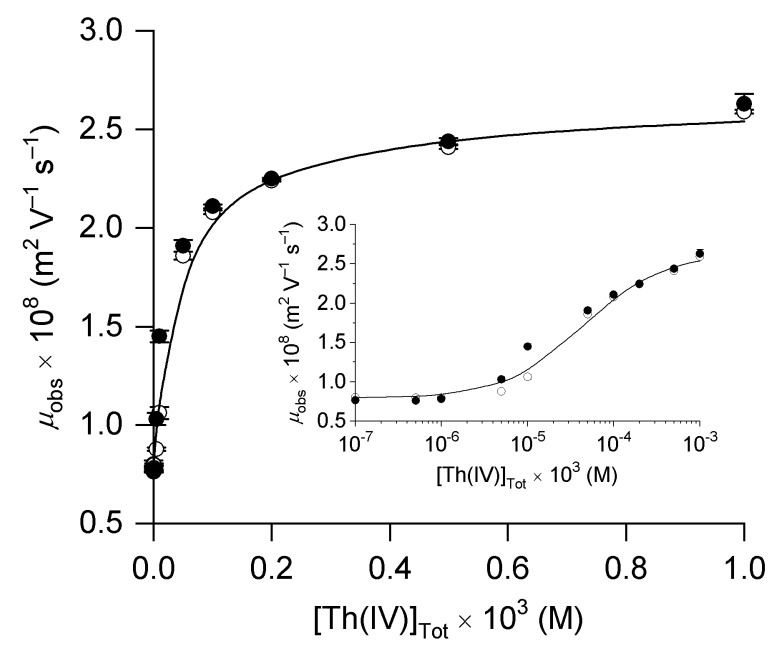

Figure 3. Variation of the observed mobility ( $\left.\mu_{\mathrm{obs}}\right)$ as a function of the total thorium(IV) concentration in the BGE at $\mathrm{p}[\mathrm{H}] 1.50$ (open circles) and 2.00 (closed circles). $I=0.1 \mathrm{M}$ $(\mathrm{H}, \mathrm{Na}) \mathrm{ClO}_{4}, T=298 \mathrm{~K}$. The dashed line corresponds to the best-fit curve at $\mathrm{p}[\mathrm{H}] 1.50$ according to Eq. (2).

Since the ligand-exchange rate exceeds by far the migration rate, the observed mobility $\mu_{\text {obs }}$ can be expressed according to Eq. (2) as the weighted sum of the mobility of each charged $\left[\mathrm{Th}_{m}(\mathrm{DFO})_{l} \mathrm{H}_{h}\right]^{(4 m+h-3 l)+}$ individual species present in the migration band. In Eq. (2), $\mu_{m l h}$ stands for the intrinsic electrophoretic mobility and $\alpha_{m l h}$ for the molar fraction given by Eq. (3) (charges are omitted) as a function of the overall apparent equilibrium constant $\beta_{m l h}$ associated to equilibrium (4). Best estimates of $\mu_{m l h}$ and $\beta_{m l h}$ were obtained by nonlinear least-squares (NNLS) refinement for a given chemical model [11].

$$
\begin{gathered}
\mu_{\mathrm{obs}}=\sum \alpha_{m l h} \mu_{m l h} \\
\alpha_{m l h}=\frac{\left[\mathrm{Th}_{m}(\mathrm{DFO})_{l} \mathrm{H}_{h}\right]}{[\mathrm{DFO}]_{\mathrm{Tot}}}=\frac{\beta_{m l h}[\mathrm{Th}]^{m}[\mathrm{DFO}]^{l}[\mathrm{H}]^{h}}{[\mathrm{DFO}]+\sum l \beta_{m l h}[\mathrm{Th}]^{m}[\mathrm{DFO}]^{l}[\mathrm{H}]^{h}} \\
m \mathrm{Th}^{4+}+l \mathrm{DFO}^{3-}+h \mathrm{H}^{+} \stackrel{\beta_{m l h}}{\rightleftarrows}\left[\mathrm{Th}_{m}(\mathrm{DFO})_{l} \mathrm{H}_{h}\right]^{(4 m+h-3 l)+}
\end{gathered}
$$

Firstly, the sole formation of mononuclear $\left[\mathrm{Th}(\mathrm{DFO}) \mathrm{H}_{h}\right]^{(h+1)+}$ complexes with one 
ligand $(m=l=1)$ was considered [5,29]. To avoid over parametrization and divergence during the NLLS refinement cycles, the first important step in numerical data analysis is to make a reasonable initial guess about the stoichiometry of the complex that prevails in solution. To that end, we made the following reasoning. As discussed above, (DFO) $\mathrm{H}_{4}{ }^{+}$occurs at very low thorium concentration levels, so $\mu_{\mathrm{obs}}$ tends to $\left.\mu_{\mathrm{LH}_{4}}=\mu_{014}=(7.8 \pm 0.2) \times 10^{-9} \mathrm{~m}^{2} \mathrm{~V}^{-1} \mathrm{~s}^{-1}\right)$. Data of Figure 3 further indicate that the complex should possess a charge higher than one owing to the increase of $\mu_{\mathrm{obs}}$, in agreement with relation (5) that expresses the electrophoretic mobility of a given species as a function of its electrical charge $z$, the charge of the electron $e$, the hydrodynamic radius $r_{\text {hyd }}$, and the viscosity of the electrolyte $\eta$.

$$
\mu_{m l h}=\frac{z e}{6 \pi \eta r_{\mathrm{hyd}}}
$$

At first approximation, it was assumed that the radius of (DFO) $\mathrm{H}_{4}{ }^{+}$is not significantly changed upon thorium binding. DFT calculations (vide infra) performed with a conductor-like polarizable continuum model (CPCM) for a dielectric constant of $\varepsilon_{0}=80$ [42], suggest a fully extended conformation for (DFO) $\mathrm{H}_{4}{ }^{+}$, while the floppy ligand is only partially wrapped around the eightcoordinate $\mathrm{Th}$ center in $\left[\mathrm{Th}(\mathrm{DFO}) \mathrm{H}_{3}\right]^{4+}$ and $\left[\mathrm{Th}(\mathrm{DFO}) \mathrm{H}_{2}\right]^{3+}$, and thus keeps an elongated shape. Hence, if $r_{\text {hyd }}\left(\left[\mathrm{Th}(\mathrm{DFO}) \mathrm{H}_{h}\right]^{(h+1)+}\right) \sim r_{\text {hyd }}\left((\mathrm{DFO}) \mathrm{H}_{4}{ }^{+}\right)$, it follows that $\mu_{11 h} \sim(h+$ 1) $\mu_{014}$. The estimated mobility values for the different species that might form are $\mu_{113} \sim 3.2 \times$ $10^{-8} \mathrm{~m}^{2} \mathrm{~V}^{-1} \mathrm{~s}^{-1}$ for $\left[\mathrm{Th}(\mathrm{DFO}) \mathrm{H}_{3}\right]^{4+}, \mu_{112} \sim 2.4 \times 10^{-8} \mathrm{~m}^{2} \mathrm{~V}^{-1} \mathrm{~s}^{-1}$ for $\left[\mathrm{Th}(\mathrm{DFO}) \mathrm{H}_{2}\right]^{3+}$, and $\mu_{111} \sim$ $1.6 \times 10^{-8} \mathrm{~m}^{2} \mathrm{~V}^{-1} \mathrm{~s}^{-1}$ for $[\mathrm{Th}(\mathrm{DFO}) \mathrm{H}]^{2+}$. Structurally, $\left[\mathrm{Th}(\mathrm{DFO}) \mathrm{H}_{3}\right]^{4+}$ and $\left[\mathrm{Th}(\mathrm{DFO}) \mathrm{H}_{2}\right]^{3+}$ correspond to mono- and bischelated complexes, respectively, while $[\mathrm{Th}(\mathrm{DFO}) \mathrm{H}]^{2+}$ can be described as well as a trishydroxamato or, most likely, as a monohydrolyzed bishydroxamato $\left[\mathrm{Th}(\mathrm{OH})(\mathrm{DFO}) \mathrm{H}_{2}\right]^{2+}$ complex owing to proton ambiguity. It should be stressed that the hydrodynamic radii of $(\mathrm{DFO}) \mathrm{H}_{4}{ }^{+}$and $\left[\mathrm{Th}(\mathrm{DFO}) \mathrm{H}_{h}\right]^{(h+1)+}$ are less and less similar as more bidentate hydroxamate groups are bound to the metal center, because the molecular shape changes progressively from a worm-like to a more compact globular structure as the ligand wraps around thorium. With this in mind, the experimental limiting mobility for the DFO peak found at $\mu_{\mathrm{obs}}=(2.5 \pm 0.1) \times 10^{-8} \mathrm{~m}^{2} \mathrm{~V}^{-1} \mathrm{~s}^{-1}$ strongly suggests that the tricationic bishydroxamato $\left[\mathrm{Th}(\mathrm{DFO}) \mathrm{H}_{2}\right]^{3+}$ species is predominant around $\mathrm{p}[\mathrm{H}] 1.5-2$ at millimolar thorium concentration levels.

NLLS fitting of the experimental data points according to Eq. (2) for a simple model 
including only (DFO) $\mathrm{H}_{4}{ }^{+}$and $\left[\mathrm{Th}(\mathrm{DFO}) \mathrm{H}_{2}\right]^{3+}$ in equilibrium returned $\log \beta_{112}=39.1$ and 38.4 at $\mathrm{p}[\mathrm{H}]=1.50$ and 2.00 , respectively. Protonation constants of $\mathrm{DFO}^{3-}$ were fixed to the values given in reference [49] at the same ionic strength, medium, and temperature (Table S2). Considering the fair agreement between both measured $\beta_{112}$ values, the retained equilibrium constant for $\left[\mathrm{Th}(\mathrm{DFO}) \mathrm{H}_{2}\right]^{3+}$ is taken as the average, $\log \beta_{112}=38.7 \pm 0.4$. The uncertainty range encompasses both individual determinations. The refined average electrophoretic mobility value is $\mu_{112}=(2.5 \pm 0.1) \times 10^{-8} \mathrm{~m}^{2} \mathrm{~V}^{-1} \mathrm{~s}^{-1}$, in very good agreement with our estimation $(2.4 \times$ $\left.10^{-8} \mathrm{~m}^{2} \mathrm{~V}^{-1} \mathrm{~s}^{-1}\right)$. Including a second complex into the model, either $\left[\mathrm{Th}(\mathrm{DFO}) \mathrm{H}_{3}\right]^{4+}$ or $[\mathrm{Th}(\mathrm{DFO}) \mathrm{H}]^{2+}$, did not improve the quality of the fit or lead systematically to reject the added species as its equilibrium constant became negative. Further attempts to analyze the data by assuming other plausible stoichiometries at $\mathrm{p}[\mathrm{H}] 2\left(\left[\mathrm{Th}_{2}(\mathrm{DFO}) \mathrm{H}\right]^{6+},\left[\mathrm{Th}(\mathrm{DFO})_{2} \mathrm{H}_{6}\right]^{4+}\right.$, $\left[\mathrm{Th}(\mathrm{DFO})_{2} \mathrm{H}_{5}\right]^{3+}$, or $\left.\left[\mathrm{Th}(\mathrm{DFO})_{2} \mathrm{H}_{4}\right]^{2+}\right)$ also failed, as the minimization procedure produced either poor fits, returned unrealistic parameters, or even diverged.

\subsection{DFT calculations}

The structure of $(\mathrm{DFO}) \mathrm{H}_{4}{ }^{+}$and $\left[\mathrm{Th}(\mathrm{DFO}) \mathrm{H}_{2}\right]^{3+}$ were optimized by DFT calculations using hybrid B3LYP functional [40], the MWB60 Stuttgart relativistic effective core potentials [41] for Th(IV), and the 6-311++G** basis set for the others elements. The $\mathrm{Th}^{4+}$ center was found to be eight coordinated, with four water molecules completing the coordination sphere at a mean $\mathrm{Th}-\mathrm{O}_{\mathrm{w}}$ distance of $2.78 \pm 0.11 \AA$. All three possible binding schemes were considered, namely coordination of $\mathrm{Th}^{4+}$ by (i) both adjacent hydroxamates remote from the terminal ammonium group (sites 1 and 2), (ii) the central and the $N$-terminal binding units (sites 2 and 3), and (iii) both terminal hydroxamate groups (sites 1 and 3). The first arrangement (binding of sites 1 and 2) afforded the most stable complex; its structure is shown in Figure 4. As expected, the mean $\mathrm{Th}-\mathrm{O}_{\mathrm{N}}$ bond length was significantly shorter $(2.32 \pm 0.05 \AA)$ than the $\mathrm{Th}-$ $\mathrm{O}_{\mathrm{C}}$ one $(2.44 \pm 0.02 \AA)$. In the bischelated complex involving both $C$-terminal hydroxamates, the rest of the molecule (a 17-atom long chain) assumes an extended conformation, with an interatomic distance of ca. $25 \AA$ between both $-\mathrm{NH}_{3}{ }^{+}$and $-\mathrm{CH}_{3}$ termini. Overall, the calculated structure for $\left[\mathrm{Th}(\mathrm{DFO}) \mathrm{H}_{2}\right]^{3+}$ closely resembles that reported for the analogous $\left[\mathrm{M}(\mathrm{DFO}) \mathrm{H}_{2}\right]^{+}$ complexes $\left(\mathrm{M}^{2+}=\mathrm{Cu}^{2+}\right.$ and $\left.\mathrm{Pb}^{2+}\right)$ [50], and moreover does not differ so much from that of the fully protonated ligand, which further supports our initial assumption on the approximate similarity between the hydrodynamic radii of the free and bischelated ligand. 

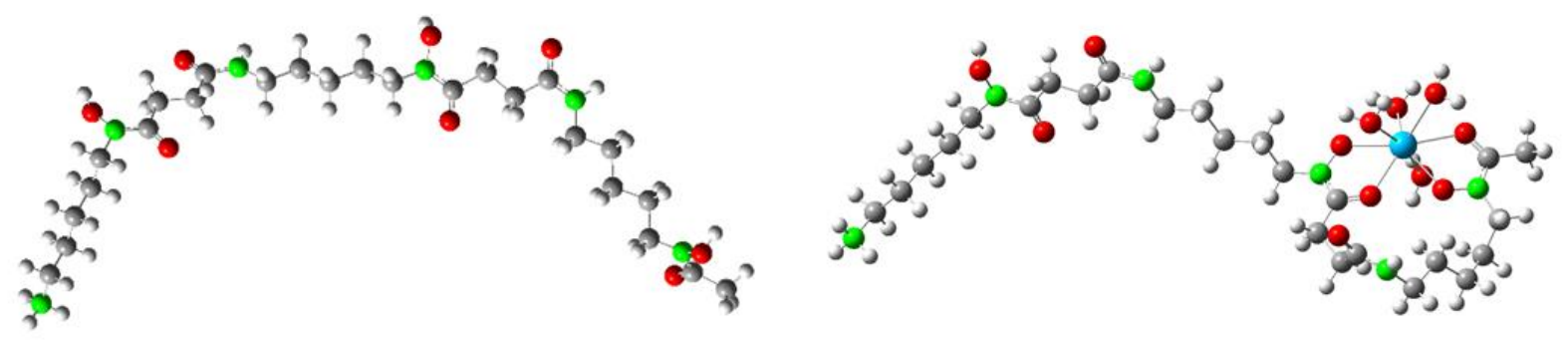

Figure 4. DFT-optimized structures of $(\mathrm{DFO}) \mathrm{H}_{4}{ }^{+}$(left) and $\left[\mathrm{Th}(\mathrm{DFO}) \mathrm{H}_{2}\right]^{3+}$ (right). Refer to the online version for the color code of the atoms: Th (blue), $\mathrm{C}$ (grey), $\mathrm{H}$ (white), $\mathrm{N}$ (green), $\mathrm{O}$ (red).

\subsection{Comparison with literature data}

ACE investigation covering a metal:ligand concentration ratio spanning 4 orders of magnitude $\left(R=10^{-3}-10\right)$ strongly supports the existence of $\left[\mathrm{Th}(\mathrm{DFO}) \mathrm{H}_{2}\right]^{3+}$ as a major species in 0.010 $0.032 \mathrm{M} \mathrm{HClO}_{4}$ solutions $(\mathrm{p}[\mathrm{H}]=1.50-2.00)$, corroborating the spectrophotometric and ${ }^{1} \mathrm{H}$ NMR results of Whisenhunt et al. $(R \sim 1, \mathrm{p}[\mathrm{H}]=0.8-2.9)$ [29]. However, our overall stability constant for $\left[\mathrm{Th}(\mathrm{DFO}) \mathrm{H}_{2}\right]^{3+}\left(\log \beta_{112}=38.7 \pm 0.4\right)$ cannot be directly compared to the value reported by these authors, because the first protonation constant of $\mathrm{DFO}^{3-}$ corresponding to the terminal amino group was not taken into account in their calculation of $\beta_{112}$. When this protonation constant $\left(\log \beta_{011}=10.89\right.$ [29]) is factored in, $\log \beta_{112}$ equals $39.40(I=0.1 \mathrm{M} \mathrm{KCl}$, $T=298.2 \mathrm{~K}$ ), in good agreement with the value measured herein by ACE at the same ionic strength and temperature.

Linear Free Energy Relationships (LFER) are useful tools for comparing the affinity of a given ligand for a series of metal cations $\left(\mathrm{M}^{z+}\right)$. Several authors have shown that the stability constant of $[\mathrm{M}(\mathrm{DFO}) \mathrm{H}]^{(z-2)+}$ complexes correlates reasonably well with the monohydroxo complex formation constant $K_{\mathrm{MOH}}$ (Eq. (6)) on a $\log -\log$ scale, indicating that the stability depends primarily on the Lewis acidity of the metal, as it is expected for an electrostatic interaction. The slope of the line reflects the basicity of the $\mathrm{RO}^{-}$donors of the chelating ligand. Moreover, a similar binding mode can also be inferred from such linear plots.

$$
\mathrm{M}^{z+}+\mathrm{OH}^{-} \stackrel{K_{\mathrm{MOH}}}{\rightleftarrows}[\mathrm{M}(\mathrm{OH})]^{(z-1)+}
$$

Figure 5 displays a similar LFER when $\log K^{\prime}{ }_{112}$ (Eqs. (7) and (8)) is plotted as a function of $\log K_{\mathrm{MOH}}$, for a series of di-, tri-, and tetravalent metal ions covering almost the 
entire periodic table. In Eq. (8) $\log \beta_{012}$ stands for the global formation constant of (DFO) $\mathrm{H}_{2}{ }^{-}$ ( $\beta_{012}=K_{011} K_{012}$, see Supporting Information). Data retrieved from the literature can be found in Table S4 and were used without any ionic strength correction, as most values were determined at $I=0.1-0.7 \mathrm{M}$. A good linear trend is observed for all cations, including $\mathrm{Th}^{4+}(\log$ $K^{\prime}{ }_{112}=18.3 \pm 0.4$ ), which provides high confidence in the accuracy and reliability of our measured value.

$$
\begin{gathered}
\mathrm{M}^{z+}+(\mathrm{DFO}) \mathrm{H}_{2}^{-} \stackrel{K_{112}^{\prime}}{\longleftarrow}\left[\mathrm{M}(\mathrm{DFO}) \mathrm{H}_{2}\right]^{(z-1)+} \\
K_{112}^{\prime}=\frac{\left[\mathrm{M}(\mathrm{DFO}) \mathrm{H}_{2}\right]}{[\mathrm{M}]\left[(\mathrm{DFO}) \mathrm{H}_{2}\right]}=\frac{\beta_{112}}{\beta_{012}}
\end{gathered}
$$

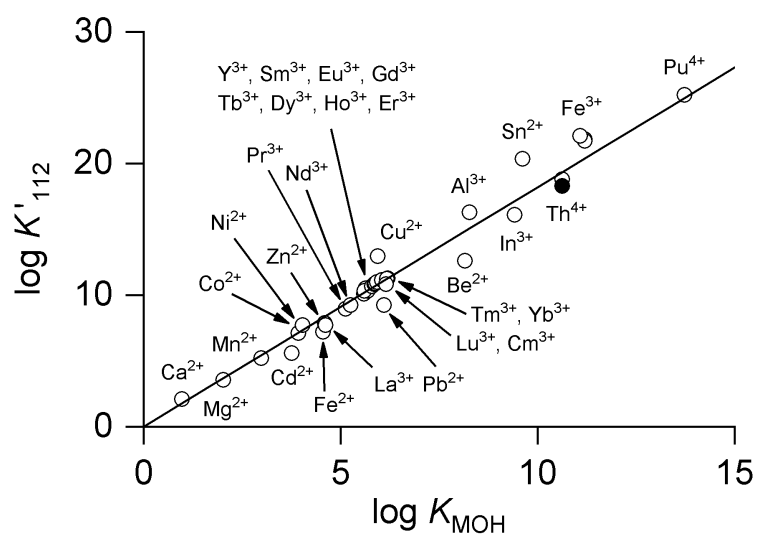

Figure 5. Plot of the apparent stability constants of $[\mathrm{M}(\mathrm{DFO}) \mathrm{H}]^{(z-2)+}\left(\log K^{\prime}{ }_{112}\right.$ as defined by Eq. (8)) as a function of the first metal hydrolysis constant (log $K_{\mathrm{MOH}}$ as defined by Eq. (6)). Data and references are summarized in Table S4 (some redundant points are omitted in the graph for sake of clarity but were included in the calculation of the regression line: slope $=$ 1.82). The black dot corresponds to the value determined in this work for $\left[\mathrm{Th}(\mathrm{DFO}) \mathrm{H}_{2}\right]^{3+}$.

\section{Conclusion}

ACE was successfully applied to the study of the Th(IV)/DFO system in acidic aqueous solutions $(\mathrm{p}[\mathrm{H}]=1.50-2.00)$. The mobility change of the DFO peak, monitored by UV absorption spectrophotometry upon increasing the Th(IV) concentration in the BGE, allowed us to straightforwardly estimate with a good accuracy the electroosmotic mobility of the predominating complex in acid solutions in which glass-electrode potentiometry becomes unreliable $(\mathrm{p}[\mathrm{H}]<2)$. Relying on the simple assumption that the hydrodynamic radius of the 
ligand is not significantly impacted upon binding to a metal center, as confirmed latter by DFT calculations, we could conclude about the charge, and thus the correct stoichiometry, of the prevailing species, namely $\left[\mathrm{Th}(\mathrm{DFO}) \mathrm{H}_{2}\right]^{3+}$. This approach turned out to be extremely helpful for implementing the right species into the chemical model prior to refining the associated stability constant by a nonlinear least-squares procedure. In many instances, fitting experimental data for systems involving multiprotic ligands, such as $\mathrm{DFO}^{3-}$, is not straightforward. For most of the analytical methods classically employed (e.g. potentiometry, absorption or emission spectrophotometry, calorimetry...), the proper selection among all hypothesized species often relies on a trial-error approach, while in some instances several models with complexes having different stoichiometries fit equally well the same datasets. In that respect, ACE appears a valuable mean to overcome such difficulties, as it enabled us to safely clear up an ambiguity that was standing for almost 25 years in the literature and to accurately measure the stability constant of $\left[\mathrm{Th}(\mathrm{DFO}) \mathrm{H}_{2}\right]^{3+}$ by consuming not more than 0.1 $\mathrm{mg}$ of chelator for more than 60 individual runs. This approach is especially valuable for unraveling the speciation of compounds available only in minute amounts, like most siderophores at the exception of Desferal ${ }^{\circledR}$. Further work is in progress for exploring the broadness of its scope.

The Agence Nationale de la Recherche (ANR project PLUTON, grant $N^{\circ}$ ANR-17CE08-0053) and the Centre National de la Recherche Scientifique (CNRS) are gratefully acknowledged for financial support. This article is also based upon work from the program "Défi NEEDS Environnement" (project PiRATE) and COST Action CA 18202 (NECTAR Network for Equilibria and Chemical Thermodynamics Advanced Research) supported by COST (European Cooperation in Science and Technology, http://www.cost.eu).

The authors have declared no conflict of interest.

\section{References}

[1] Templeton, D. M., Ariese, F., Cornelis, R., Danielsson, L.-G., Muntau, H., van Leeuwen, H. P., Lobinski, R., Pure Appl. Chem. 2000, 72, 1453-1470.

[2] Hummel, W., Filella, M., Rowland, D., Sci. Total Environ. 2019, 692, 49-59.

[3] Moulin, C., Amekraz, B., Hubert, S., Moulin, V., Anal. Chim. Acta 2001, 441, 269-279. 
[4] Moulin, C., Amekraz, B., Colette, S., Doizi, D., Jacopin, C., Lamouroux, C., Plancque, G., J. Alloys Compd. 2006, 408-412, 1242-1245.

[5] Keith-Roach, M. J., Vetri Buratti, M., Worsfold, P. J., Anal. Chem. 2005, 77, 7335-7341.

[6] Sornosa-Ten, A., Jewula, P., Fodor, T., Brandès, S., Sladkov, V., Rousselin, Y., Stern, C., Chambron, J.-C., Meyer, M., New J. Chem. 2018, 42, 7765-7779.

[7] Terencio, T., Roithová, J., Brandès, S., Rousselin, Y., Penouilh, M.-J., Meyer, M., Inorg. Chem. 2018, 57, 1125-1135.

[8] Timerbaev, A. R., Chem. Rev. 2013, 113, 778-812.

[9] Timerbaev, A., Timerbaev, R., Trends Anal. Chem. 2013, 51, 44-50.

[10] Galievsky, V. A., Stasheuski, A. S., Krylov, S. N., Anal. Chem. 2015, 87, 157-171.

[11] Sladkov, V., Electrophoresis 2016, 37, 2558-2566.

[12] Olabi, M., Stein, M., Wätzig, H., Methods 2018, 146, 76-92.

[13] Solinova, V., Zakova, L., Jiracek, J., Kasicka, V., Anal. Chim. Acta 2019, 1052, 170-178.

[14] Štěpánová, S., Kašička, V., J. Sep. Sci. 2015, 38, 2708-2721.

[15] Ehala, S., Kašička, V., Makrlík, E., Electrophoresis 2008, 29, 652-657.

[16] Ehala, S., Míšek, J., Stará, I. G., Starý, I., Kašička, V., J. Sep. Sci. 2008, 31, 2686-2693.

[17] Varenne, F., Bourdillon, M., Meyer, M., Lin, Y., Brellier, M., Baati, R., Charbonnière, L. J., Wagner, A., Doris, E., Taran, F., Hagège, A., J. Chromatogr. A 2012, 1229, 280-287.

[18] Topin, S., Aupiais, J., Baglan, N., Vercouter, T., Vitorge, P., Moisy, P., Anal. Chem. 2009, $81,5354$.

[19] Sladkov, V., Electrophoresis 2010, 31, 3482-3491.

[20] Sladkov, V., J. Chromatogr. A 2013, 1289, 133-138.

[21] Sladkov, V., J. Chem. Thermodyn. 2014, 71, 148-154.

[22] Sladkov, V., Bessonov, A. A., Roques, J., Charushnikova, I. A., Fedosseev, A. M., New J. Chem. 2018, 42, 7780-7788.

[23] Alexandre, J.-C., Dacheux, N., Aupiais, J., Radiochim. Acta 2018, 106, 801.

[24] Willberger, C., Leichtfuß, D., Amayri, S., Reich, T., Inorg. Chem. 2019, 58, 4851-4858.

[25] Aupiais, J., Alexandre, J.-C., Sicre, R., Siberchicot, B., Topin, S., Moisy, P., Dacheux, N., Eur. J. Inorg. Chem. 2020, 2020, 216-225.

[26] Sladkov, V., Fourest, B., David, F., Venault, L., Lecomte, M., Anal. Bioanal. Chem. 2003, $376,455-459$.

[27] Meyer, M., Burgat, R., Faure, S., Batifol, B., Hubinois, J.-C., Chollet, H., Guilard, R., C. R. Chimie 2007, 10, 929-947. 
[28] Jewula, P., Berthet, J.-C., Chambron, J.-C., Rousselin, Y., Thuéry, P., Meyer, M., Eur. J. Inorg. Chem. 2015, 2015, 1529-1541.

[29] Whisenhunt, D. W., Neu, M. P., Hou, Z. G., Xu, J., Hoffman, D. C., Raymond, K. N., Inorg. Chem. 1996, 35, 4128-4136.

[30] Stintzi, A., Raymond, K. N., Siderophore Chemistry in: Templeton, D. E. (Ed.), Molecular and Cellular Iron Transport, Marcel Dekker, New York 2001, pp. 273-319.

[31] Butler, A., Theisen, R. M., Coord. Chem. Rev. 2010, 254, 288-296.

[32] Raines, D. J., Sanderson, T. J., Wilde, E. J., Duhme-Klair, A. K., Siderophores in: Reedijk, J. (Ed.), Elsevier Reference Module in Chemistry, Molecular Sciences and Chemical Engineering, Elsevier, Waltham, MA 2015, pp. 1-32.

[33] John, S. G., Ruggiero, C. E., Hersman, L. E., Tung, C. S., Neu, M. P., Environ. Sci. Technol. 2001, 35, 2942-2948.

[34] Xu, C., Zhang, S., Kaplan, D. I., Ho, Y.-F., Schwehr, K. A., Roberts, K. A., Chen, H., DiDonato, N., Athon, M., Hatcher, P. G., Santschi, P. H., Environ. Sci. Technol. 2015, $49,11458-11467$.

[35] Kiss, T., Farkas, E., J. Inclusion Phenom. Macrocycl. Chem. 1998, 32, 385-403.

[36] Sladkov, V., J. Chromatogr. A 2012, 1263, 189-193.

[37] Sladkov, V., J. Chromatogr. A 2013, 1276, 120-125.

[38] Gaš, B., Electrophoresis 2009, 30, S7-S15.

[39] Frisch, M. J., Trucks, G. W., Schlegel, H. B., Scuseria, G. E., Robb, M. A., Cheeseman, J. R., Scalmani, G., Barone, V., Mennucci, B., Petersson, G. A., Nakatsuji, H., Caricato, M., Li, X., Hratchian, H. P., Izmaylov, A. F., Bloino, J., Zheng, G., Sonnenberg, J. L., Hada, M., Ehara, M., Toyota, K., Fukuda, R., Hasegawa, J., Ishida, M., Nakajima, T., Honda, Y., Kitao, O., Nakai, H., Vreven, T., Montgomery, J. A., Peralta, J. E., Ogliaro, F., Bearpark, M. J., Heyd, J., Brothers, E. N., Kudin, K. N., Staroverov, V. N., Kobayashi, R., Normand, J., Raghavachari, K., Rendell, A. P., Burant, J. C., Iyengar, S. S., Tomasi, J., Cossi, M., Rega, N., Millam, N. J., Klene, M., Knox, J. E., Cross, J. B., Bakken, V., Adamo, C., Jaramillo, J., Gomperts, R., Stratmann, R. E., Yazyev, O., Austin, A. J., Cammi, R., Pomelli, C., Ochterski, J. W., Martin, R. L., Morokuma, K., Zakrzewski, V. G., Voth, G. A., Salvador, P., Dannenberg, J. J., Dapprich, S., Daniels, A. D., Farkas, Ö., Foresman, J. B., Ortiz, J. V., Cioslowski, J., Fox, D. J., Gaussian 09, Gaussian, Inc., Wallingford, CT 2009.

[40] Becke, A. D., J. Chem. Phys. 1993, 98, 5648.

[41] Küchle, W., Dolg, M., Stoll, H., Preuss, H., J. Chem. Phys. 1994, 100, 7535-7542. 
[42] Barone, V., Cossi, M., J. Phys. Chem. A 1998, 102, 1995-2001.

[43] Rand, M. H., Fuger, J., Grenthe, I., Neck, V., Rai, D., Chemical Thermodynamics of Thorium, OECD Publishing, Paris 2008.

[44] Sladkov, V., He, M., Jewula, P., Penouilh, M.-J., Brandès, S., Stern, C., Chambron, J.-C., Meyer, M., J. Radioanal. Nucl. Chem. 2018, 318, 259-266.

[45] Jiang, C., Armstrong, D., Electrophoresis 2010, 31, 17-27.

[46] Farkas, I., Grenthe, I., Banyai, I., J. Phys. Chem. A 2000, 104, 1201-1206.

[47] Östhols, E., Geochim. Cosmochim. Acta 1995, 59, 1235-1249.

[48] Chen, C., Wang, X., Appl. Radiat. Isot. 2007, 65, 155-163.

[49] Hernlem, B. J., Vane, L. M., Sayles, G. D., Inorg. Chim. Acta 1996, 244, 179-184.

[50] Schijf, J., Christenson, E. A., Potter, K. J., Mar. Chem. 2015, 173, 40-51. 